\title{
Exposure to mass media malaria messages and use of insecticide-treated nets and artemisinin combination therapy among Southeast Nigeria residents
}

\author{
Chidiebere A. Nwachukwu \& Luke I. Anorue \\ Department of Mass Communication, \\ University of Nigeria, Nsukka \\ Email:Chidiebere.nwachukwu@unn.edu.ng
}

\begin{abstract}
Background: Malaria remains endemic in Nigeria. The National Malaria Elimination Programmeutilizes the mass media to educate Nigerians to adopt insecticide-treated nets (ITNs) and Artemisinin Combination Therapy (ACT) for malaria prevention and treatment respectively. This study investigated the influence of media messages on ITN and ACT use in Southeast Nigeria.

Methods: Data was collected with a structured questionnaire from 480 respondents across 15 communities in Southeast Nigeria. Analysis was carried out on the data using percentages and logistic regression.

Results: Results indicated high exposure to malaria messages, but limited effect on ITN and ACT use. Regression results showed that exposure to newspapers $(O R=1.017)$; magazines $(O R=1.639)$ and internet $(O R=1.444)$ increased the odds of ITN use. Exposure to television messages $(O R=I .707 ; P<0.00 \mathrm{I})$; billboards $(O R=2.098 ; P<0.0 \mathrm{II})$; Internet $(\mathrm{OR}=\mathrm{I} .805 ; \mathrm{P}<0.0 \mathrm{II}) \quad$ and tertiary education $(O R=8.454 ; p<0.000)$ positively predicted $A C T$ use.

Conclusions: Exposure to malaria messages has not resulted in population-wide adoption of ITNs and ACT. There is need for the National Malaria Elimination Programme to address factors that hinder ITN and ACT use.
\end{abstract}

Keywords: Exposure, mass media messages, malaria, Insecticide-treated Nets, Artemisinin Combination Therapy

\section{Introduction}

Malaria has been on the global health agenda for more than six decades now. Despite the appreciable achievement recorded in the global fight against the disease evidenced by reduction in mortality from about one million in the 1990s to 446,000 currently (World Health Organisation, 2018), Nigeria remains the most malaria endemic country in the world. Nigeria alone accounts for $27 \%$ of malaria cases globally and $24 \%$ of malaria deaths annually. About three out of 10 persons having malaria in the world live in Nigeria and one out of four deaths from malaria globally occurs in Nigeria (Obinna, 20/8). The sum of these statistics is that malaria kills 107,040 Nigerians every year or 293 people daily. Nigeria therefore, is important in the global efforts to eliminate malaria.

The Nigerian malaria control programme emphasises the use of insecticide-treated nets for malaria prevention as well as Artemisinin Combination Therapy (ACT) for malaria treatment. With malaria becoming resistant to chloroquine and other malaria drugs in many regions of the world, ACT has become the first line treatment for malaria.
The World Health Organisation (WHO) in 200I recommended ACTs as first line treatment for malaria because of their efficacy and potential to limit drug resistance (WHO, 2006; Akoria and Arhuidese, 2014).

Progress recorded so far in global malaria control through ITNs and ACT has given the world renewed hope that malaria could ultimately be eliminated globally. While the World Health Organisation has set the target of eliminating malaria in 35 countries by 2030, the Nigeria Malaria Elimination Programme (NMEP) has set the goal of achieving elimination by 2020 , barely two years away. This goal is unattainable without a population-wide adoption of appropriate malaria preventive and treatment measures by Nigerians. To ensure this the NMEP has continued to use behaviour change communication via the mass media to educate and persuade Nigerians on the need to sleep under insecticide-treated nets and use Artemisinin Combination Therapy for malaria prevention and treatment respectively. It is important to find out how effective the media campaign has been in inducing the targeted behaviour change. 
While there is no guarantee that a health campaign will be successful, several studies have indicated a correlation between exposures to health communication and use of ITNs (Adjah and Panayiotu, 2014; Apo, Kwankye and Badasu, 2015; Bowen, 2013; Ankomah, Adebayo, Arogundade, Anyati, Nwokolo, et al, 20I4; Kilian, Lawford, Ujuju, Abeku, Nwokolo, Okoh and Baba, 2016).

The link between communication interventions and use of the nets may be accounted for by the fact that such interventions are effective in raising knowledge about the cause, transmission, symptoms and severity of malaria, as well as the benefits of ITNs as prevention tools. Studies in Nigeria (Uzochukwu and Nwuneli, 2016; Amusan, Umar and Vantsawa, 2017; Okpoko and Aniwada, 2017, Killian, et al, 2016); Cameroon (Kimbi, Nkesa, NdamukongNyanga, Sumbele, Atashili and Atanga, 2014) and Tanzania (Edson and Kayombo, 2007) indicate a high knowledge of malaria facts among the study populations. Appropriate knowledge can make a difference between acceptance and rejection of malaria control measures. Ankomah, et al (2014) found that knowledge that sleeping under the nets prevents malaria was significantly associated with sleeping under a net, while Killian, et al (2016) found that such knowledge increased with exposure to behaviour change communication. Despite increasing knowledge of malaria, misconceptions remain. For instance, some believe that malaria is an air-borne disease, a virus in the blood, a disease of palm wine, a disease caused by eating unhygienic food, and drinking dirty water (Kimbi, et al, 20l4; Nyirongo, 2013; Asanti, Abokyi, Zandoh, Owusu, Suleman, et al, 20I0).

Exposure to malaria-related messages and knowledge of the disease do not guarantee ready acceptance and adoption of the promoted prevention and treatment measures. Even where people possess ITNs and are convinced of their efficacy, some still refuse to use them. Scholars have therefore reported a gap between ITN ownership and usage. (Berkessa, Ojira and Tesfa, 2016; Omole, Ogunfowokan and Moses, 2017; Aderebigbe, Olatona, Sogunro, Alawole, Oluwole, et al, 20l4; Chukwuocha, Dozie, Onwuliri, Ukagu, Nwoke, et al, 20II; Ogunsami, Essang, Olaoye, Solademi and Makinde, 2016; AlEryani, Mahdy, Al-Mekhlafi and Abdul-Ghani, 20I7).

As knowledge of malaria and ITN and possession of nets do not guarantee use of ITNs, scholars have examined other intervening variables that impinge on the use of ITNs. One of such factors is education. Many studies have found a positive association between higher levels of education with positive attitude to ITN use. Even in the case of under-five year old children, it has been found that the 4643 educational level of the household head is correlated with odds of the children sleeping under the nets (Arogundade, et al, 20I I; Astatkie and Faleke, 2009; Seyoum, Speybroeck, Duchateau, Brandt and RosasAguirre 2017). One plausible reason for the edge educated people appear to have over the uneducated in the malaria discourse may be that they possess stronger cognitive ability by virtue of their education which predisposes them to understand facts about malaria more than the uneducated.

Socioeconomic status has also been empirically proved to influence adoption of malaria control measures. In a study in Cote d'Ivoire for instance, Esse, Utzinger, Tshannen, Raso, Pfeiffer, et al, (2008) found that the wealthiest members of the society not only correctly attributed malaria to mosquito bites, but were more likely to adopt effective malaria control measures. However, those in the lowest economic quintile were found to not only attribute malaria to the sun but used fumigating coils more. Other studies in Mozambique and Nigeria reported similar findings (Moon, Hayes, Blevins, Lopez, Green, et al, 2016; Onwujekwe, Hanson and For, 2004; Anyaehie, Nwagha, Aniebue and Nwagha, 20II). However there are studies (Goesch, Schwarz, Decker, Oyakhirome, Borchet, et al, 2008; DakoGyeke and Kofie, 20I5; Mora-Ruiz, Penilla, Ordonez, Lopez, Solis, et al, 20I4) that show people of low economic status more likely to use bed nets.

Scholars have also found some negative perceptions and misconceptions associated with nonuse of the bed nets. For instance, studies have shown that many are unwilling to use ITNs as a result of perceived harmful effects of the chemicals used in treating the nets. Some for instance fear that the chemicals will cause chronic diseases, kill unborn children and cause sterility (Arogundade, et al, 20l I; Nnko, Whyte, Geissler and Aagaard-Hansen, 2012; Taramwa, Ashaba, Ayebazibire, Omoding,Hilliard, et al, 2017; Ugwu, Ezechukwu, Obi, Ugwu and Okeke, 20I2). Other utilisation-related barriers include complaints against excessive heat, difficulty in breathing and discomfort caused by the nets (Jombo, Gyuse, Enenebeaku, Okwori, et al, 20l0; Manu, Boamah-Kaali, Febir, Anyipah, Owusu-agyei and Asanti, 2017, Ezema, Ezema and Akor, 2014).

Research equally shows that place of residence (urban versus rural) can influence attitude to malaria control. Several studies have indicated rural-urban differences in ownership and utilisation of ITNs with variations in the findings. Birhanu, et al (20I5); Astatkie and Faleke (2009) as well as Aung, Wei, McFarland, Aung and Khin, (2016) found lower ownership of ITNs in urban areas than rural areas. One explanation for this might be that many nations usually give preference to rural areas in long lasting 
insecticide-treated net distribution campaigns. Despite the foregoing, there are other studies that show rural-urban differences in favour of urban areas (Inungu, Ankiba, Minelli, Mumford, Bolekale..Raji, 20I 7; Belay and Deressa, 2008).

Whenever malaria prevention is unsuccessful the emphasis shifts to effective case management. The National Malaria Elimination Programme's policy on malaria control in Nigeria recommends Artemisininbased Combination Therapy as first line treatment for malaria in line with World Health Organisation (WHO) directive. Few studies on the use of ACTs for malaria treatment reveal poor utilisation of the drug. Mazigo et al (2010) in a study in Tanzania found a poor use of ACT among the study population despite high awareness of the drug. The finding is consistent with other studies in Nigeria and Cameroon (Adeyemo, Oluwatosin,Osuala, Oladapo and LawalAdeyemo, 2017; Sayang, Gausseres, Vernazza-Light, Malvy, Bley and Millet, 2009). The study in Cameroon focused on health professionals and even they indicated poor use of ACTs. Further evidence of low ACT use comes from Romay-Barja, Nkogo, Nsenga, Santana-Morales, Berzosa...Benito (2018) and Romay-Barja, Jarrin, Ncogo, Nseng, Sagrado... and Benito (20I5). A different result was observed in Benin where it was found that ACT was among the commonly used drugs (Damien, Aguemon, Alfa, Bocossa, OOuyemi-Hounto, Remoue and Hesran, 2018).

One explanation for the poor utilisation of ACTs may be the increasing reliance on local herbal medications for malaria treatment. Ekwunife, Ukwe and Awanye (2010) as well as Onyeneho (2013); Mazigo, et al (2010) and Adeyemo, et al (2017) all found that herbs were popular among their study populations for malaria treatment. Another reason for poor ACT utilisation is the tendency to "mix" drugs. This refers to the practice of combining doses of different drugs to treat malaria. Anyanwu, Fulton, Evans and Paget (2017) found in a study in Nigeria that all respondents from rural areas reported that they mixed. This is corroborated by another work in Nigeria where Onyeneho (2017) found that all the respondents were reported to have engaged in "mixing of medicine" as first line of treatment.

While the mass media have an edge in reaching vast numbers of people, they could be complemented by interpersonal communication. Some studies have found an association between interpersonal communication and respondents' willingness to use bed nets (Russel, Sallau, Emukah, Graves, Noland...Patterson, 2015; Killian, et al, 2016). Other studies have found interpersonal communication as the dominant source of information about malaria control (Kimbi, et al, 2014; Apo, et al, 2016).

While there are many malaria-related studies most of them have been on insecticide-treated nets. Scholars have paid scant attention to the use of Artemisinin combination therapy despite its critical role in malaria control. This study seeks to fill the gap by examining the influence of mass media messages on the use of both insecticide-treated nets and Artemisinin combination therapy. The study was guided by three research questions: To what extent are Southeast residents exposed to mass media malaria messages; How has exposure to mass media malaria messages influenced use of insecticidetreated nets and Artemisinin combination therapy for malaria prevention and treatment; and what other factors influence the use of insecticide-treated nets and Artemisinin combination therapy among Southeast residents?

\section{Theoretical framework}

The Diffusion of Innovation Theory, propounded by Everett Rogers in 1962 traces and describes how innovative ideas, products and practices spread within an organisation, community or society or from one society to another (Rimer and Glanz, 2005). It equallyshows how such innovations are communicated via certain channels over time among members of a social system (Rogers, 1962, cited in Rimer and Glanz, 2005).

This theory assigns roles to both mass media and interpersonal communication. While the mass media may inform and influence early adopters, they in turn use interpersonal communication to influence opinion leaders, who in turn influence others in the social system (Baran and Davis, 2012:333). Five categories of people are identified by the theory with respect to the speed with which they adopt promoted innovations: The innovators, early adopters, early majority, late majority, and the laggards. This categorisation which implies a difference in individuals' level of acceptance and resistance to innovations (Schiavo, 20I4:37) shows that knowledge of an innovation alone does not translate into in its adoption.

\section{Data/Methods:}

The study was conducted across 15 communities including rural and urban areas in Southeast Nigeria comprising five states (Abia, Anambra, Ebonyi, Enugu and Imo). The study made use of the survey research method. The sample size for the study was 480 respondents. The sample size was calculated by means of the Wimmer and Dominick's Online Sample Size Calculator using a 95\% confidence level and 5\% error margin. 
The state capitals were purposively selected to ensure the addition of urban perspective to the study, while two wards were selected through simple random sampling from the official list of electoral wards in each state. Convenience sampling was used to select the respondents in each study area.

A structured questionnaire, containing both openended and closed-ended questions, was used to collect data from the 480 respondents. To overcome the barrier of illiteracy in many of the study areas, the questionnaire was read in the local lgbo language where necessary, with the answers coded by trained research assistants. And to make up for copies of the questionnaire which might either not be returned or would be filled wrongly, and consequently rendered unusable, replacement copies were provided.

The study made use of two dependent/outcome variables of the use of insecticide-treated nets (ITNs) and Artemisinin Combination Therapy (ACT) for malaria prevention and treatment. The respondents were asked if they slept under ITNs for malaria prevention, and if they used ACT for malaria treatment. For each of the outcome variables, their responses were then grouped into $I=y e s$ if they use any of ITN or ACT and $0=$ no if they did not use any of ITN or ACT.

The major independent variable for this study is exposure to mass media messages on malaria prevention and treatment. The exposure to mass media message was derived from the following media channels; radio, television, newspapers, magazines, billboards, and internet. For each of these media channels, respondents who were exposed to it were coded I (yes) while respondents not exposed to any particular media channel were coded 0 (no).

Individual- level explanatory variables used were gender (male/female), age (less than 30, 30-49, $50+$ years), education (none/primary, secondary, tertiary), marital status (never married, married, widowed/divorced), employment status (unemployed/student, farmer/businessman, civil servant), income (up to $\mathrm{N} 20,000, \mathrm{~N} 2 \mathrm{I}, 000-\mathrm{N} 50,000$, more than $\mathrm{N} 50,000$ ), place of residence (urban/rural)

The data were analysed by means of the Statistical Package for the Social Sciences (SPSS). Percentages were used to describe the study population and exposure to malaria messages by respondents. In addition, percentages were used to highlight the use of insecticide-treated nets and ACT for malaria prevention and treatment respectively. The results of these descriptive analyses were presented in tables. Finally, logistic regression was used to estimate the factors that predict respondents' use of insecticidetreated nets and Artemisinin combination therapy.

\section{Results}

Table I: Demographic characteristics of respondents

\begin{tabular}{llllll}
\hline Demographic variable & Enugu & Anambra & Imo & Ebonyi & Abia \\
\hline Sex & & & & & \\
Male & $49.57 \%$ & $42.73 \%$ & $55.56 \%$ & $62.83 \%$ & $60.42 \%$ \\
Female & $50.43 \%$ & $57.27 \%$ & $44.44 \%$ & $37.18 \%$ & $39.58 \%$ \\
Age & & & & & \\
Less than 29years & $13.04 \%$ & $34.55 \%$ & $34.57 \%$ & $20.51 \%$ & $27.08 \%$ \\
$30-49 y e a r s$ & $43.48 \%$ & $43.64 \%$ & $37.04 \%$ & $42.31 \%$ & $41.67 \%$ \\
50 years + & $43.48 \%$ & $21.82 \%$ & $28.40 \%$ & $37.18 \%$ & $31.25 \%$ \\
Employment & & & & & \\
Unemployed/Student & $23.48 \%$ & $30.00 \%$ & $23.46 \%$ & $42.31 \%$ & $28.13 \%$ \\
Farmer/businessman & $37.39 \%$ & $32.73 \%$ & $40.74 \%$ & $26.92 \%$ & $44.79 \%$ \\
Civil Servant & $39.13 \%$ & $37.27 \%$ & $35.80 \%$ & $30.77 \%$ & $27.08 \%$ \\
Marital Status & & & & & \\
Never Married & $11.50 \%$ & $29.09 \%$ & $22.22 \%$ & $28.21 \%$ & $26.04 \%$ \\
Married & $73.45 \%$ & $65.45 \%$ & $71.60 \%$ & $52.56 \%$ & $65.63 \%$ \\
Divorced/Widowed & $15.04 \%$ & $5.45 \%$ & $6.17 \%$ & $19.23 \%$ & $8.33 \%$
\end{tabular}




\section{Educational Attainment}

$\begin{array}{llllll}\text { Primary Education/lliterate } & 28.70 \% & 8.18 \% & 14.81 \% & 24.36 \% & 19.79 \% \\ \text { Secondary Education } & 31.30 \% & 32.73 \% & 25.93 \% & 25.64 \% & 23.96 \% \\ \text { Tertiary Education } & 40.00 \% & 59.09 \% & 59.26 \% & 50.00 \% & 56.25 \% \\ \text { Income } & & & & & \\ \text { Up to } 20,000 & 17.76 \% & 44.44 \% & 41.77 \% & 32.05 \% & 30.45 \% \\ 21,000-50,000 & 57.94 \% & 41.67 \% & 26.58 \% & 37.18 \% & 34.04 \% \\ 51,000+ & 24.30 \% & 13.89 \% & 31.65 \% & 30.77 \% & 35.11 \% \\ \text { Place of Residence } & & & & & \\ \text { Urban } & 40.00 \% & 65.45 \% & 74.07 \% & 56.41 \% & 43.75 \% \\ \text { Rural } & 60.00 \% & 34.55 \% & 25.93 \% & 43.59 \% & 56.25 \%\end{array}$

A total of 480 respondents were studied comprising $256(53.3 \%)$ males and 224 (46.7\%) females. Of this number, II5 were from Enugu state, 110 from Anambra, 8I from Imo, 78 from Ebonyi and 96 from Abia states. The age distribution of the respondents shows that 29 were less than 20; 94 (19.6\%) were aged between 20 and $29 ; 105$ (21.9\%) were in the 40-49 age bracket while 82 (I7.1\%) were aged 50 59. Fifty two respondents (10.8\%) were aged $60-69$ while $22(4.6 \%)$ were aged 70 and above.

The respondents were made up of 317 married people; 16 divorced and 37 widowed people while II 0 fell under the never married category. There were 32 respondents without formal education, 60 (I2.5\%), I 36 (28.3\%), 92 (19.2\%) and 160 (13.7\%) with primary, secondary, diploma and first degree to doctoral education respectively. Income levels ranged from less than 10,000 Naira to more than 100,000 Naira per month. In addition, there were 265 (55.2\%) urban dwellers and 215 (44.8\%) rural dwellers.

\section{Exposure to mass media malaria messages}

A total of 450 (93.75\%) respondents reported being exposed to mass media malaria messages. Radio was the greatest source of exposure to malaria messages among the respondents with $380(79.2 \%)$ indicating that they were exposed to radio messages. This was followed by television with 249 (5I.9\%); internet (94/19.6\%); newspapers (69/14.4\%); billboards $(58 / 12.1 \%)$ and magazines $(41 / 8.5 \%)$. However, information on ITNs and ACT was also received through interpersonal communication from healthcare personnel like doctors and nurses. For instance, $265(55.2 \%)$ respondents were exposed to malaria information through doctors while 205(42.7\%) did through nurses and $124(25.8 \%)$ got information from patent medicine dealers. In addition $367(76.4 \%)$ indicated that they trust doctors most http://aps.journals.ac.za for malaria information followed by $97(20.2 \%)$ who trust nurses most.

Use of insecticide-treated nets among Southeast Nigeria residents

Results indicated that 402 respondents (83.75\%) owned ITNs while 78 (16.25\%) did not own any. Of those that owned nets, 74 (I5.4\%) had one net; 155 (32.29\%) possessed two nets while I73 (36.04\%) had more than two nets. The greatest sources of the ITNs were government free net distribution campaigns (226/47.08\%), followed by ITN gifts at hospitals (1 $13 / 23.54 \%)$. Those who purchased their own were 52 (10.8\%). Others got theirs at health centres.

The respondents were asked if they actually slept under an ITN the night preceding the survey. While 402 respondents owned ITNs, and 375 (78.12\%) expressed confidence in the efficacy of ITNs to prevent malaria, only 203 (42.3\%) indicated that they slept under an ITN the night preceding the survey. Others employed a range of prevention measures including drugs, herbs, mosquito coils and window and door screens.

In addition, 250 (52.1\%) indicated they had challenges using ITNs while 230 (47.9\%) said they had none. The challenges ranged from complaints about heat and feelings of suffocation (224/46.7\%) and the fear that the chemicals used in treating the nets were harmful to people (I0I/2I\%); 32 (6.7\%) said they did not know how to hang the nets.

Use of Artemisinin Combination Therapy for Malaria Treatment

About one half of the respondents (238/49.6\%) correctly identified ACT as the drug promoted for malaria treatment. An open-ended question was used to ask which drug the respondents used in treating malaria. Respondents indicated a variety of drugs they 
take for malaria treatment with 237 respondents representing $49.37 \%$ of the respondents mentioning a variety of ACTs. The drugs in this category mentioned by the respondents included Coartem, Lonart, Amatem, Lumartem, and Arthemeter Lumenfantrine. The rest comprising more than half of the respondents mentioned other non-ACT drugs like herbal medicine, chloroquine, Amala, Malareich, Laridox, etc. The implication is that there is yet no wholesale adoption of the mass media promoted Artemisinin Combination Therapy for malaria treatment in the study areas. However, it appears that some use ACTs in ignorance, because when they were asked in a close-ended question if they used ACTs for malaria treatment, 209 (43.5\%) said yes; 27 I $(56.5 \%)$ said no. In addition, I8I (37.7\%) saw ACT as the best drug for malaria treatment; 77 (16.1\%) did not while $222(46.2 \%)$ were not sure.

Table 2: Regression results for influence of mass media malaria messages on ITN and ACT use

\begin{tabular}{lll}
\hline Variables & $\begin{array}{l}\text { Model I } \\
\text { ITN USE } \\
\text { Odds ratio }\end{array}$ & $\begin{array}{l}\text { Model 2 } \\
\text { ACT USE } \\
\text { Odds ratio }\end{array}$ \\
\hline Radio: No (RC) & 1.000 & 1.000 \\
Yes & 0.718 & 0.924 \\
Television: No(RC) & 1.000 & 1.000 \\
Yes & 0.687 & $1.707^{*}$ \\
Newspapers: NO(RC) & 1.000 & 1.000 \\
Yes & 1.017 & 0.594 \\
Magazines: No(RC) & 1.000 & 1.000 \\
Yes & 1.639 & 0.697 \\
Billboards: No (RC) & 1.000 & 1.000 \\
Yes & 0.816 & $2.098^{*}$ \\
Internet: No (RC) & 1.000 & 1.000 \\
Yes & 1.444 & $1.805^{*}$ \\
\hline
\end{tabular}

The regression results for the influence of exposure to media messages on the use of ITNs and ACT as shown in Table 2 indicated weak association between such exposure and the use of ITNs and ACTs. In Model I which shows the effect of mass media messages on the use of ITNs, exposure to radio, television and billboards messages decreased the odds of ITN use. Exposure to newspaper messages $(O R=1.017)$; magazine messages $(O R=1.639)$ and internet $(O R=1.444)$ increased the odds of ITN use.
In model 2 exposure to malaria messages through radio, newspapers and magazines decreased the odds of ACT use. However, results indicated that those who were exposed to television messages $(\mathrm{OR}=1.707 ; \mathrm{P}<0.00 \mathrm{I})$ were $\mathrm{I} .7$ times more likely to treat malaria with ACT. Those who were exposed to billboard messages were 2.0 times more likely to use ACTs $(O R=2.098 ; P<0.0 \mathrm{II})$ while exposure to internet messages $(O R=1.805 ; P<0.01 \mathrm{I})$ increased the odds of ACT use by 1.8 times.

Table 3: Socioeconomic predictors of ITN ACT USE

\begin{tabular}{lll}
\hline Variables & $\begin{array}{l}\text { Model I } \\
\text { ITN USE } \\
\text { Odds ratio }\end{array}$ & $\begin{array}{l}\text { Model 2 } \\
\text { ACT USE } \\
\text { Odds ratio }\end{array}$ \\
\hline Sex: Male (RC) & 1.000 & 1.000 \\
Female & 0.949 & 0.845 \\
Age:Less than 29 (RC) & 1.000 & 1.000 \\
$30-49$ & 0.678 & 0.542 \\
50 years + & 0.824 & $0.453^{*}$ \\
Marital status: & & \\
Never married(RC) & 1.000 & 1.000 \\
Married & 1.377 & 1.303 \\
Divorced/widowed & 1.534 & 0.889 \\
Education & & \\
Illiterate/Primary (RC) & 1.000 & 1.000 \\
Secondary & 2.111 & $4.072^{* *}$ \\
Tertiary & $5.178^{* * *}$ & $7.993^{* * *}$ \\
\hline
\end{tabular}




\begin{tabular}{lll}
\hline Employment & & \\
Unemployed/student(RC) & 1.000 & 1.000 \\
Farmer/businessman & 1.711 & 1.217 \\
Civil servant & $2.101^{*}$ & 1.345 \\
Income & & \\
Up to $20,000(\mathrm{RC})$ & 1.000 & 1.000 \\
$31,000-50,000$ & 0.797 & $0.547^{*}$ \\
$5 \mathrm{I}, 000+$ & 0.679 & 1.262 \\
State & 1.000 & 1.000 \\
Enugu(RC) & $3.308^{* * *}$ & $2.411^{* *}$ \\
Anambra & 1.249 & 0.806 \\
Imo & $19.315^{* * *}$ & $2.273^{*}$ \\
Ebonyi & 0.888 & $1.362^{*}$ \\
Abia & & \\
Place of residence & 1.000 & 1.000 \\
Urban (RC) & 1.078 & 0.853 \\
Rural & & \\
\hline
\end{tabular}

Table 3 shows the regression results for socioeconomic predictors of ITN and ACT use. In model I a number of independent variables such as 30-49 year-olds as well as those 50 years and above; those earning an income of $31,000-50,000$ and 51,000 and above; and being residents of Abia were associated with decreased odds of ITN use. However, results indicated that married people $(\mathrm{OR}=1.377)$ and the divorced/widowed $(O R=1.534)$ had increased odds of ITN use relative to those in the never married category. In addition, secondary education $(O R=2.1 \mathrm{II})$ and tertiary education $(O R=5.178 ; P<0.000)$ increased the odds of ITN use. In the employment category, farmers/businessmen $(O R=1.712)$ were 1.7 times more likely to sleep under the nets relative to the unemployed/students while civil servants $(O R=2.10 I)$ were 2.1 times more likely to sleep under ITNs. Being residents of Anambra state $(O R=3.308 ; P<0.000)$; Imo state $(O R=1.248)$ and Ebonyi state $(O R=19.315$; $\mathrm{P}<0.000$ ) increased the likelihood of ITN use. Results equally indicated that rural dwellers $(O R=1.078)$ were 1.07 times more likely to sleep under ITNs relative to urban dwellers.
Data on model 2 show that such independent variables as females, 30-49 year-olds; 50 year-olds and above $(O R=0.824 ; \quad p<0.038)$; the divorced/widowed; those earning $31,000-50,000$; residents of Imo state and rural dwellers were associated with decreased odds of ACT use. Married people $(O R=1.304)$ were found to be 1.3 times more likely to use ACTs relative to the never married. Those with secondary $(O R=4.072$; $\mathrm{p}<0.00 \mathrm{I})$ and tertiary education ( $\mathrm{OR}=7.993$; $\mathrm{p}<0.000$ ) had significantly increased odds of ACT use. In the employment category results indicated that farmers/businessmen $(O R=1.217)$ were 1.21 times more likely to use ACT relative to the unemployed just as civil servants $(O R=1.346)$ were I. 3 times more likely to treat malaria with ACT. In addition, being residents of Anambra state $(O R=2.4 \mathrm{I}$; $p<0.008)$, Ebonyi state $(O R=2.273$; $p<0.024)$ and Abia state $(O R=1.363)$ were associated with increased likelihood of ACT use. Rural dwellers $(O R=0.853)$ had decreased odds of $A C T$ use relative to urban residents.

Table 4: Regression results of combined mass media and socio-economic predictors of ITN and ACT use

\begin{tabular}{lll}
\hline Variables & $\begin{array}{l}\text { Model I } \\
\text { ITN USE } \\
\text { Odds ratio }\end{array}$ & $\begin{array}{l}\text { Model 2 } \\
\text { ACT USE } \\
\text { Odds ratio }\end{array}$ \\
\hline Mass media & & \\
Radio: No(RC) & 1.000 & 1.000 \\
Yes & 0.571 & 1.236 \\
Television: No(RC) & 1.000 & 1.000 \\
Yes & $0.433^{*}$ & 1.107 \\
Newspapers: No (RC) & 1.000 & 1.000 \\
Yes & 0.923 & $0.411^{*}$ \\
\hline
\end{tabular}

http://aps.journals.ac.za 


\begin{tabular}{|c|c|c|}
\hline Magazines : No(RC) & 1.000 & 1.000 \\
\hline Yes & 1.463 & 0.622 \\
\hline Billboards: No(RC) & 1.000 & 1.000 \\
\hline Yes & 1.046 & $2.268^{*}$ \\
\hline Internet: No (RC) & 1.000 & 1.000 \\
\hline Yes & 1.285 & 1.288 \\
\hline Sex: Male:No (RC) & 1.000 & 1.000 \\
\hline Female & 0.946 & 0.845 \\
\hline \multicolumn{3}{|l|}{ Age } \\
\hline Up to $29(\mathrm{RC})$ & 1.000 & 1.000 \\
\hline $30-49$ years & 0.606 & 0.528 \\
\hline 50 years + & 0.798 & $0.414 *$ \\
\hline \multicolumn{3}{|l|}{ Marital status } \\
\hline Never married(RC) & 1.000 & 1.000 \\
\hline Married & 1.732 & 1.362 \\
\hline Divorced/widowed & $1.71 \mathrm{I}$ & 0.946 \\
\hline \multicolumn{3}{|l|}{ Education } \\
\hline Illiterate/Primary (RC) & 1.000 & 1.000 \\
\hline Secondary & 2.347 & $4.655^{* *}$ \\
\hline Tertiary & 6.452 & $8.455^{* * * *}$ \\
\hline \multicolumn{3}{|l|}{ Employment } \\
\hline Unemployed/students(RC) & 1.000 & 1.000 \\
\hline Farmer/businessman & 1.747 & 1.191 \\
\hline Civil servant & 2.051 & 1.375 \\
\hline \multicolumn{3}{|l|}{ Income } \\
\hline Up to $20,000(R C)$ & 1.000 & 1.000 \\
\hline $31,000-50,000$ & 0.839 & $0.511 *$ \\
\hline $51,000+$ & 0.828 & 1.123 \\
\hline \multicolumn{3}{|l|}{ State } \\
\hline Enugu(RC) & 1.000 & 1.000 \\
\hline Anambra & 3.002 & $2.653^{* *}$ \\
\hline Imo & 1.131 & 0.855 \\
\hline Ebonyi & 21.945 & $2.721^{*} *$ \\
\hline Abia & 0.914 & 1.483 \\
\hline \multicolumn{3}{|l|}{ Place of residence } \\
\hline Urban(RC) & 1.000 & 1.000 \\
\hline Rural & 1.069 & 0.870 \\
\hline
\end{tabular}

Table 4 shows the regression results of the combined effects of exposure to mass media messages and socioeconomic characteristics on the use of ITNs and ACT. In model I it can be observed that exposure to messages through radio, television and newspapers was associated with decreased odds of ITN use. Television $(O R=0.433 ; p<0.002)$ particularly was found to significantly decrease the likelihood of sleeping under ITNs. However, those exposed to magazine messages $(O R=1.466)$ were 1.4 times more likely to sleep under ITNs than those who were not just as billboards $(O R=1.046)$ and the internet $(\mathrm{OR}=1.285)$ increased the odds of sleeping under the nets.

In addition, married people $(O R=1.732)$ and the divorced/widowed $(O R=1.7 I I)$ were found to be I.7 times more likely to sleep under ITNs relative to 4649 the never married category. Secondary education $(O R=2.347 ; \mathrm{p}<0.039)$ and tertiary education $(O R=6.452 ; \quad p<0.000)$ were associated with significantly increased likelihood of ITN use. In the employment category, results indicated that farmers/businessmen $(\mathrm{OR}=1.747)$ were 1.7 times more likely to use ITNs relative to the unemployed/students while civil servants $(O R=2.05 I ; p<0.044)$ were 2 times more likely to use ITNs relative to the unemployed. Furthermore, residents of Anambra state $(O R=3.002 ; p<0.001)$; Imo state $(O R=1.131)$; Ebonyi state $(O R=21.945 ; p<0.000)$ had significantly increased likelihood of ITN use while being a resident of Abia decreased the odds. Rural residents were also found to be 1.06 times more likely to sleep under ITNs relative to urban dwellers.

http://aps.journals.ac.za 
In model 2 which depicts the combined effects of mass media messages and socioeconomic characteristics on ACT use, independent variables like newspapers and magazines, females, ages 30-49 and 50 and above; divorced/widowed; income level of 3I,000-50,000; residents of Imo state and rural dwellers were all associated with decreased odds of $A C T$ use. Exposure to radio messages $(O R=1.236)$; television $\quad(\mathrm{OR}=\mathrm{I} .107) ; \quad$ billboards $(O R=2.268 ; p<0.023)$ and the Internet $(O R=1.288)$ increased the likelihood of using ACT for malaria treatment. Exposure to newspaper messages $(O R=0.4 I I ; p<0.014)$ was found to significantly decrease the odds of ACT use.

In the age category, those aged 50 and above $(O R=0.414 ; p<0.023)$ had significantly decreased odds of using $A C T$. Data equally indicated that married people $(O R=1.362)$ were I.3 times more likely to treat malaria with $A C T$ relative to those in the never married category.

Results indicated also that education has strong effect on the use of ACT. For instance, secondary education $(O R=4.655 ; p<0.00 \mathrm{I})$ and tertiary education $\quad(O R=8.454 ; \quad P<0.000)$ significantly increased the likelihood of ACT use. In the employment category, results indicated that farmers/businessmen $(O R=I .19 I)$ were $I . I$ times more likely to use ACT while civil servants $(O R=1.375)$ were 1.3 times more likely to use ACT relative to the unemployed. While those earning $31,000-50,000$ had decreased odds of using ACT, those earning above $50,000(\mathrm{OR}=\mathrm{I} .123)$ were I.I times more likely to do so.

Moreover, residents of Anambra state $(O R=2.652 ; p<0.005)$ and Ebonyi state $(O R=2.721 ; p<0.009)$ had significantly increased likelihood of treating malaria with ACT. In the same vein, Abia state residents $(O R=1.483)$ were 1.4 times more likely to use ACT relative to Enugu residents. Residents of Imo state however, were associated with decreased odds of using ACT just as rural residents had decreased odds of treating malaria with $A C T$ relative to urban residents.

\section{Discussion}

This study found a high level of exposure to malariarelated messages among Southeast residents as $93.75 \%$ indicated that they had heard/seen/read the messages through various mass media. This high level of exposure is consistent with other studies in Ghana and Nigeria (Adjah and Panayiotu, 20l4; Apo, et al, 2015; Uzochukwu and Nwuneli, 2016;) where exposure to mass media malaria messages ranged from $84.1 \%$ to $98 \%$.

The dominant medium of exposure was radio, followed by television. The dominance of radio as an effective medium for health communication is well reported in other studies (Belay and Deressa, 2017; Adjah and Panayiotu, 20l4; Sultana, et al, 2016). However, respondents indicated reliance on other sources for information on malaria including doctors, nurses, patent medicine dealers, family members, etc. But the most trusted sources were doctors and nurses, clearly showing the importance of interpersonal communication in malaria control efforts. Other studies have found that interpersonal communication is not only associated with increased odds of using ITNs, but in some cases is the dominant source of information about malaria control (Russel, et al,20 I5; Killian, et al, 20I6, Kimbi,et al, 20।4; Apo, et al, 2015). The importance of interpersonal communication can be explained by the diffusion of innovation theory which assigns roles to both the mass media and interpersonal communication and goes further to suggest that the mass media influence opinion leaders who in turn influence others.

Despite 423 (88.12\%) respondents hearing of ITNs through the mass media and 402 (83.75\%) owning nets, only 203 (42.3\%) actually slept under an ITN the night preceding the survey. The rest used other measures like drugs, mosquito coils, herbs, etc. This indicates knowledge-practice and ownershipusage gaps, showing that knowledge of, and possession of ITNs do not guarantee use. This ownership-usage gap has been reported in other studies (Birhanu, 2015; Omole, et al, 2017; Aderebigbe, et al, 20I4; Arogundade, et al, 20II, AlEryani, et al, 2017). The reason for the net ownership-use gap may be partially explained by reported complaints associated with net use in addition to negative perceptions of the nets. Such complaints and negative perceptions include discomfort with the net, fears that the chemicals in the net are harmful and could cause cancer, sterility, etc, a result that is consistent with other studies (Nnko, et al, 20l2; Taramwa, et al, 2017, Ukwu,20l2).

Results also showed that both knowledge and use of ACTs for malaria treatment have not become diffuse. While 237 (49.37\%) mentioned a variety of ACT drugs they take for malaria treatment, when asked if they take ACT, only 209 (43.5\%) indicated that they do. This shows that some use ACTs ignorantly, indicating that they have not got to the point of consciously asking for and insisting on ACTs. This low utilisation of ACTs was also found by Mazigo, et al, 2010; Adeyemo, et al, 20l7and Sayang, et al, 2009. The poor utilisation of ACTs may be because of reliance on herbs and mono-therapies which have been proven ineffective. Furthermore, the respondents engage in "drug mixing" which has 
been reported in other studies also (Anyanwu, Fulton, Evans and Paget, 20I7).

The results of the regression analyses revealed a weak association between mass media messages and use of ITNs and ACT. In the rural areas, despite the fact that radio and television were the dominant media of exposure to malaria messages; they (radio and television messages) predicted decreased odds of using ITNs and ACT while newspapers, magazines, and the internet increased the odds. Television, billboards and the internet messages however increased the odds of ACT use in the urban and rural areas. This result is at variance with many studies which have found a strong link between exposure to radio and television messages and use of ITNs and ACT (Adjah and Panayiotu, 2014;Belay and Deresa, 2008; Sultana, et al, 2017; Uzochukwu and Nwuneli, 2016). It may also be an indication that mass media messages are not enough to persuade people to adopt promoted measures. Some studies have highlighted the effectiveness of interpersonal communication involving healthcare workers in achieving high utilisation of ITNs and ACT (Russel, Sallau, Emukah, Graves, Noland...Patterson, 2015; Killian, et al, 2016).

The socioeconomic predictors of ITN use were found to be secondary education, tertiary education and being civil servants. The ability of education to positively predict ITN $(p<0.04 I)$ and ACT $(p<0.000)$ use has been well reported in other studies (Arogundade, et al, 20I I; Astatkie and Faleke, 2009; Seyoum, Speybroeck, Duchateau, Brandt and RosasAguirre 2017). When mass media and socioeconomic characteristics were combined the odds ratio of some independent variables changed indicating that other variables apart from the mass media influence uptake of ITN and ACT.

It is important to highlight an inherent weakness in this study. While the study covered the five states in the Southeast region of Nigeria compared to some studies that covered a few towns/communities, the sample size used may be too small to make the result universally generalisable. To achieve that would require a much larger sample size.

\section{Conclusion}

The study found a high exposure to mass media malaria messages among Southeast Nigeria residents. However, exposure to the messages has not resulted in population-wide adoption of the promoted ITNs and ACTs as less than half of the respondents reported using ITN and ACT. There is need therefore, not only to continue to use behaviour change communication to persuade the populace to use the prevention and treatment tools, but to supplement this effort with interpersonal 4651 communication involving healthcare personnel to ensure society-wide adoption of insecticide-treated nets and Artemisinin combination therapy.

\section{References}

Aderebigbe, S. A., Olatona, F. A., Sogunro, O., Alawade, G., Oluwole, A. B. ... et al. (20|4). "Ownership and utilization of long lasting insecticide-treated nets following free distribution campaign in Southwest Nigeria." Pan African Medical Journal, 17: 263.Doi: 10.1 I604/pamj.2014.17.263.3927.

Adeyemo, M. O. A., Oluwatosin, A., Osuala, E. O., Oladapo, M. M. and Lawal-Adeyemo, A. A. (2017)."Awareness and utilization of artemisininbased combination therapies among mothers of under-five children in a local government area in Nigeria." App. Sci. Report, 17(2):35-40Doi: 10.15।92/PSCP.ASR.20I7.17.23540

Adjah, E. S. O. and Panayiotu, A. G. (20/4). "Impact of Malaria related messages on insecticide-treated net (ITN) use for malaria prevention in Ghana." Malaria Journal,

13:123 www.malariajournal.com/content/I 3/I/I 23

Akoria, O.A. and Arhuidese, I.J. (20I4). "Progress toward elimination of malaria in Nigeria: Update of Artemisinin-based combination therapies for the treatment of malaria in households in Benin City." Annals of African Medicine, I 3 (3): I04-I I 3

Al-Eryani, S. M. A., Mahdy, M. A. K., Al-Mekhlafi, A. M. and Abdul-Ghani, R. (20|7). "Access to and use of LLINs and factors associated with non-use among communities in malaria-endemic areas of Al Hudaydah governorate in the Tihama region, West of Yemen." Malaria Journal.16: 244.Doi: I0.1 I86/s|2936-017-I894-9

Amusan, V. O., Umar, Y. A. and Vantsawa, P. A. (2017). "Knowledge, attitudes and practices on malaria prevention and control among private security guards within Kaduna Metropolis, Kaduna State - Nigeria." Science Journal of Public Health, 5(3): $240-245$.

Ankomah, A., Adebayo, S. B., Arogundade, E. D., Anyati, J., Nwokolo, E., Inyang, U., Ipadeola, O. B. and Meremikwu, M. (20I4). "The effect of mass media campaign on the use of insecticide-treated bed nets among pregnant women in Nigeria."Malaria Research and Treatment, 2014: 694863.Doi: 10.1 155/2014/694863

Anyaehie,U.S.B; Nwagha, U.I; Aniebue, P.N. and Nwagha, T.U. (20II). "The effect of free distribution of insecticide-treated nets on asymptomatic plasmodium parasitemia in pregnant and nursing mothers in a rural Nigerian community." Journal of Clinical Practice Nigeria, I4 (I): 19-22 
Anyanwu, P. E., Fultan, J., Evans, E. and Paget, T. (2017)."Exploring the role of socioeconomic factors in the development and spread of antimalaria drug resisteance: a qualitative study.”Malaria Journal, I6: 203.Doi: | |86/s |29360।7-|849-|

Apo, S. B., Kwankye, S. O. and Badasu, D. M. (20I5). "Exposure to malaria prevention messages and insecticide treated bed net usage among children under five years in Ghana." European Scientific Journal, vol. I I (I8): 290 - 305.

Arogundade, E. D., Adebayo, S. B., Anyati, J., Nwokolo, E., Ladipo, O., Ankomah, A. and Meremikwu, M. M. (20I I)."Relationship between caregivers' misconception and non-use of ITNs by under-five Nigeria children." Malaraia Journal, 10: 170. www.malariajournal.com/content/ / 0/I/I 70

Asante, K. P., Abokyi, I., Zandoh, C., Owusu, R., Suleman, A., Amenga, E., Adda R., Boahan, O., Segbaya, S., Mahama, E., Bart-Plange, C., Chandramohan, D. and Owusu-Agyei, S. (2010). "Community perceptions of malaria and malaria treatment behaviour in a rural district of Ghana: Implications for Artemisinin combination therapy." BMC Public Health, 10: 409. Doi: 10.1/86/|47|2458-10-409

Astatkie, A. and Feleke, A. (2009). "Utilization of insecticide treated nets in Arbaminch Town and the malarious villages of ArbaminchZuria District, Southern Ethiopia." Ethiopia Journal of Health Dev. 23(3): $206-215$.

Aung, T., Wei, C., McFarla, W., Aung, Y. K. and Khin, H. S. S. (2016)."Ownership and use of insecticidetreated nets among people living in malaria endemic areas of Eastern Myanmar."PLoSONE, II(9), eol62292 Doi: 10.1371/journal.pone.0162292

Belay, M. and Deressa, W. (2008). "Use of insecticide-treated nets by pregnant women and associated factors in a predominantly rural population in northern Ethiopia." Tropical Medicine and International Health, I3(10): 1303 |3|3. Doi: |0.1 | | |/j.| 365.2008.02 |59.x

Berkessa, T., Ojira, D. and Tesfa, B. (20/6). "Insecticide-treated nets use and its determinant among settlers of southwest Ethiopia." BMC Public Health, 16: I06.Doi: 10: | |86/s |2889-0162768-8

Birhanu, Z., Abebe, L., Sadhakar, M., Dissanyake, G., Yihdego, Y., Alemayehu, G. and Yewhalaw, D. (20I5). "Access to and use gaps of insecticidetreated nets among communities in Jimma Zone, Southwestern Ethiopia: baseline results." BMC Public Health, I5: I 304.Doi: I0. I 186/s I 2889-0 I52677-2
Bowen, H. L. (20I3). "Impact of a mass media campaign on bed net use in Cameroon."Malaria Journal, 12, 36. Retrieved June 23, 2017 from http://www.malariajournal.com/content/I2/I/36

Chukwuocha, U. M., Dozie, I. N. S., Onwuliri, C. O. E., Ukaga, C. N., Nwoke, B. E. B., Nwankwo, B. O. et al. (20lI). "Perceptions on the use of insecticide-treated nets in parts of Imo River Basin, Nigeria: Implications for preventing malaria in pregnancy." African Reprod.Health., I4(I): II7 $-128$.

Dako-Gyeke, M. and kofie, H. M. (2015)."Factors influencing prevention and control of malaria among pregnant women resident in Urban Slums, Southern Ghana." African Journal of Reproductive Health, I9(I): $44-53$.

Damien, B. G., Aguemon, B., Alfa, D. A., Bocossa, D., Ogouyemi-Hounto, A., Remoue, F. and Hesran, J. Y. L. (20|8). "Low use of artemisinin-based combination therapy for febrile children under five and barriers to correct fever management in Benin: a decade after WHO recommendation." BMC Public Health, 18:168. Doi: 10.1 186/s 128890I8-5077-6

Edson, F. and Kayombo, E. J. (2007)."Knowledge on malaria transmission and its prevention among school children in Kyela District, South Western Tanzania." Tanzania Health Research Bulletin, vol. 9(3), 207

Ekwunife, O. I., Ukwe, C. V. and Awanye, A. M. (20I0)."Knowledge and treatment seeking pattern of malaria infection in Abakaliki, Ebonyi State." Research Journal of Pharmaceutical, Biological and Chemical Sciences, vol. I(2): $317-323$

Esse, C., Utzinger, J., Tschannem, A. B., Raso, G., Pfeiffer, C., Granado, S. ... et al. (2008). "Social and cultural aspects of malaria and its control in central Coted" Ivoire."Malaria Journal, 7, 224.Doi: I0: I | 86/ |475-2875-7-224

Ezeama, M., Ezeama, F. and Akor, Q. G. (20/4). "Factors militating against the use of insecticide treated nets among pregnant women in Nigeria." International Journal of Research in Medical and Health Sciences, vol. 4(9), 8 - 14.

Fayehun, O.A. and Salami, K.K. (20/4)."Older persons and malaria treatment in Nigeria." African Population Studies, 27(2 supp): 424-43

Fotso, J.C., Bellhouse, L., Vessel, L. andjezman, Z. (20I5).”Strengthening the home-to-facility continuum of newborn and child healthcare through mhealth: Evidence from an intervention in rural Malawi.” African Population Studies (Special edition): 166-1682

Goesch, J. N., Schwarz, N. G., Deeker, M. L., Oyakhirome, S., Borchert, L. B. et al. (2008). "Socioeconomic status is inversely related to bed 
net use in Gabon.” Malaria Journal, 7, 60. Doi: I 0: I | 86/ / 475-2875-7-60

Inungu, J. N., Ankiba, N., Minelli, M., Numford, V., Bolekala, D. ... Raji, D. (20/7). "Use of insecticide-treated mosquito net among pregnant women and guardians of children under five in the Democratic Republic of the Congo.” Malaria Research and Treatment, vol. 2017, I - 3. Doi: I0.1156/2017/5923696

Jombo, G. T. A., Mbaawuaga, E. M., Gyuse, A. N., Enenebeaku, M. N. O., Okwori, E. E. ... et al. (2010). "Socio-cultural factors influencing treated bed net utilization in a malaria endemic city in North-Central Nigeria." Asian Pacific Journal of Tropical Medicine, 20I0, $402-406$.

Kilian, A., Lawford, H., Ujuju, C. N., Abeku, T. A., Novokolo, E., Okoh, F. and Baba, E. (2016). "The impact of behavior change communication on the use of insecticide treated nets: a secondary analysis of ten post-campaign surveys from Nigeria." Malaria Journal, 15: 422 Doi: | 0. I | 86/5 | 2936-0|6-|463-7

Kimbi, H. K., Nkesa, S. B., Ndamukong-Nyanga, J. L., Sumbele, U. N., Atashili, J. and Atanga, M. S. B. (2014). "Knowledge and perceptions towards malaria prevention among vulnerable groups in the Buea health district, Cameroon." BMC Public Health, 14, 883.

Manu, G., Boamah-Kaali, E. B., Febir, L. G., Ayipah, E., Owusu-Agyei, S. and Asante, K. P. (2017)."Low utilization of insecticide-treated bed net among pregnant women in the middle belt of Ghana."Malaria Research and Treatment, 2017: I7. Doi: I0.II55/2017/48/210.

Mazigo, H. D., Obasy, E., Mauka, W., Manyiri, P., Zinga, M., ....Heukelbach, J. (20I0). "Knowledge, attitudes and practices about malaria and its control in rural northwest Tanzania." Malaria Research and Treatment, vol. 2010: I- 9.Doi: 10.406/20 I 0/79426 |

Moon, T. D., Hayes, C. B., Blevins, M., Lopez, M. L., Goseen, A. F. ... et al. (2016). "Factors associated with the use of mosquito bed nets: results from two cross-sectional household surveys in Zambezia province, Mozambique." Malaria Journal, I5, I96.Doi: I0.1 I86/s|2936-0|6-I250-5

Mora-Ruiz, Penilla, R. P., Ordonez, J. G., Lopez, A. D., Solis, F., ... et al. (20|4). "Socioeconomic factors, attitudes and practices associated with malaria prevention in the coastal plain of Chiapas, Mexico." Malaria Journal, 13, 157. Doi: I0.1 I 86/ I475-2875-I3-157.

Nnko, S. E., Whyte, S. R., Geissler, W. P. and Aaganard-Hansen, J. (20I2). "Skepticism towards insecticide treated mosquito nets for malaria control in rural community in north-western
Tanzania.” Tanzania Journal of Health Research, vol. I4(2), I - Doi: I0.43 |4/thrd.v|4i2.2

Nyirongo, T. S. (20/3). "Communication interventions and their role in malaria prevention and prevalence: a case study of Kaole." Published Master's Dissertation submitted to the University of Zambia. Retrieved Aug. 15, 2017 from Dspace.unza.zm:8080/xmlai/bitstream/handle// 23 456789/Nyirongo.pdf

Ogunmola, O. J., Oladosu, Y. O., Olamoyegun, M. A. (20/4). "Relationship between socioeconomic status and HIV infection in a rural tertiary health centre." HIV/AIDS_(Auckland, N.z), 6, 6I - 67.

Okpoko, C. C. and Aniwada, E. C. (2017)."Issues in malaria communication in Enugu, Southeast Nigeria." Mediterranean Journal of Social Sciences, vol. 8(I): 285 - 292.

Omole, T. M., Ogunfowokan, O. and Moses, A. (2017)."Use of insecticide-treated net and malaria parasitemia in under-fives at National Hospital, Abuja." International Journal of Tropical Medicine, 23(3): I - 17.

Onyeneho, N. (20/3). "Sleeping under insecticidetreated nets to prevent malaria in nigeria. What do we know?" J. Health PopulNutr., 3I (2): 243 251.

Romay-Barja, M. Jarmri, I., Ncogo, P. Nseng, G., Sagrado, M. J. ... Benito, A. (20I5). "Rural-Urban differences in household treatment-seeking behavior for suspected malaria in children at Bata district, Equatorial Guinea." PLOS ONE, 10 (9):eol 38518

Romay-Barja, M., Ncogo, P., Nseng, G., SantanaMorales, M. A., Berzosa, P. ... Benito, A. (2018). "The use and preference of artemether as a firstchoice treatment for malaria: result from a crosssectional survey in the Bata district, Equatorial Guinea. Malaria Journal 17, 107 Doi: I0. I |86/s | 2936-0| 8-2254-0

Russel, C. L., Sallau, A., Emukah, E., Graves, P. M., Noland, G. S. ... Patterson, A. E. (20I5). "Determinants of bed nets use in Southeast Nigeria following mass distribution of LLINs: Implications for social behavior change interventions." PLoS ONE, I0(I0), e0 39447 Doi: I0.137I/journal/pone.0139447

Sayang, C., Gausseres, M., Vernazza-Lient, N., Malvy, D., Bley, D. and Millet, P. (2009)."Treatment of malaria from monotherapy to artemisinin-based combination therapy by health professionals in urban health facilities in Yaounde, central province, Cameroon." Malaria Journal, 8, I 76 Doi: I0.1 I86/I475-2875-8-I 76

Seyoum, D., Speybroeck, N., Duchateau, L., Brandt, P. and Rosas-Aguirre, A. (20|7). "Long lasting insecticide net ownership, access and use in 
Southwest Ethiopia: A community based crosssectional study."International Journal of Environmental Research and Public Health and Public Health, $14,1312$.

Taramwa, I. M., Ashaba, S., Adrama, H. O., Ayebazibire, C., Omoding, D., ... Hilliard, R. (20|7). "Knowledge, attitude and behavior towards the use of insecticide treated mosquito nets among pregnant women and children in rural southwestern Uganda." BMC Public Health, 17, 794.

Ugwu, E. O., Ezechukwu, P. C., Obi, S. N., Ugwu, A. O. and Okeke, T. C. (20/2). "Utilization of insecticide treated nets among pregnant women in Enugu, South Eastern Nigeria." Nigeria Journal of Clinical Practice, 16(3): 292 - 296

Uzochukwu, C. E. and Nwuneli, O. (2016). "Many older mothers and caregivers are not responding positively to Roll Back Malaria Campaign Intervention Messages in Southeast Nigeria." IOSR Journal of Humanities and Social Sciences. Vol $21(5):$ II - 22.

World Health Organisation (2006). WHO briefing on malaria treatment guidelines and artemisinin monotherapies. Retrieved Nov.25, 2018 from www.who.int/malaria/publications/atoz/meetingbriefing | 7April.pdf 